\title{
Analyzing the Effect of Intensive and Low-Input Agrotechnical Support for the Physiological, Phenometric, and Yield Parameters of Different Maize Hybrids Using Multivariate Statistical Methods
}

\author{
A. Illes $\mathbb{C}^{1},{ }^{1}$ C. Bojtor $\mathbb{D}^{1},{ }^{1}$ A. Szeles $\mathbb{D},{ }^{1}$ S. M. N. Mousavi $\mathbb{D},{ }^{1}$ B. Toth $\mathbb{D}^{2},{ }^{2}$ and J. Nagy $\mathbb{D}^{1}$ \\ ${ }^{1}$ Institute of Land Utilisation Technology and Regional Development, \\ Faculty of Agricultural and Food Sciences and Environmental Management, University of Debrecen, Debrecen, Hungary \\ ${ }^{2}$ Institute of Food Science, Faculty of Agricultural and Food Sciences and Environmental Management, University of Debrecen, \\ Debrecen, Hungary
}

Correspondence should be addressed to A. Illes; illes.arpad0820@gmail.com

Received 28 December 2020; Revised 29 January 2021; Accepted 8 February 2021; Published 18 February 2021

Academic Editor: Vera Popovic

Copyright ( 2021 A. Illes et al. This is an open access article distributed under the Creative Commons Attribution License, which permits unrestricted use, distribution, and reproduction in any medium, provided the original work is properly cited.

\begin{abstract}
Improving nitrogen efficiency is a crucial strategy for developing sustainable agricultural systems that leads to maximum yield in exchange for minimum inputs and nitrogen loss. Three maize hybrids (Zea mays L.) of different maturity classes and length of vegetation period (FAO 400, FAO 490, and FAO 380) were selected and for trials during the 2019 growing season. Three different nitrogen $(\mathrm{N})$ fertilization treatments $\left(0,120\right.$, and $\left.305 \mathrm{~kg} \cdot \mathrm{N} \cdot \mathrm{ha}^{-1}\right)$ were applied in order to assess variability in yield-related components. The effect of hybrids, fertilizer, and the interaction of the examined hybrids in relation to fertilizer was significant on yield and oil and protein content. Correlation and biplot analysis show that increases in the lipid peroxidation (LP) amount in the plant leaf stages cause a decrease in the oil content of the harvested yield. The activity of ascorbate peroxidase (APX) and LP at the six-leaf stage directly affects the protein content. The amount of APX at the silking stage has a direct and significant effect on starch content. This study showed that the activity of APX at the silking stage has the highest value in all examined hybrids. APX and LP can be controlled with nitrogen fertilization under various environmental circumstances.
\end{abstract}

\section{Introduction}

In today's agriculture, intensification and proper hybrid selection are essential for sustainable, profitable economic activity. Producers can choose from hundreds of approved maize hybrids on the European market to find the right genotype for their environmental conditions and production standards after obtaining proper information about the hybrids. The aim of this research is to develop a hybrid testing system, i.e., a study mostly based on physiological and plant physiological parameters, which may be supplemented with photometric, yield, and quality parameters.

Plants are often exposed to oxidative stress generated by both biotic and abiotic factors. Oxidative stress is an excessive level of reactive oxygen species (ROS) in a plant. ROS production in biological systems may occur enzymatically and nonenzymatically [1]. When plants are exposed to environmental stress, the number of reactive oxygen species in the cell increases, damaging the cell membrane [2].

Antioxidants can reduce the amount of ROS in a plant cell. Several enzymes are extremely sensitive to hydrogen peroxide $\left(\mathrm{H}_{2} \mathrm{O}_{2}\right)$ in chloroplasts, which may inhibit $\mathrm{CO}_{2}$ sequestration. Therefore, they should be converted to harmless compounds as soon as possible $[3,4]$. The most significant detoxifying process is called the ascorbate-glutathione cycle. The key enzyme in the ascorbate-glutathione cycle is ascorbate peroxidase (APX). Ascorbate peroxidase catalyzes the process in which a specific electron donor plays a role where $\mathrm{H}_{2} \mathrm{O}_{2}$ is converted to $\mathrm{H}_{2} \mathrm{O}$ [2]. Ascorbatespecific peroxidases play an essential role in the decomposition of $\mathrm{H}_{2} \mathrm{O}_{2}$ in both chloroplasts and cytosol [5]. 
Ascorbate peroxidase plays a significant role in detoxification processes and has been shown in several studies in the counterbalance of various plant stress processes, such as drought stress, heavy metal pollution, temperature stress, increased light intensity, and increased dissolved salinity in the soil [6-13].

Recent studies suggest that reactive lipid species formed by lipid peroxidation may be utilized by cells in several ways. Hard evidence supports the view that signaling mediated by reactive lipid species is involved in several physiological processes, including apoptosis and the induction of antioxidant defense [14]. Towards the end of the growing season, $\mathrm{H}_{2} \mathrm{O}_{2}$ accumulates in the plant, which is due to the increased lipid peroxidation on the one hand and the process of natural ageing of the plant on the other [15]. A substantial part of the applied fertilizers is nitrogen, which has a significant effect on the plant's physiological processes. Regarding the physiological responses of maize, the question arises as to how the antioxidant defense system reacts and what effect it has on lipid peroxidation. Zhang et al. [16] showed that high-dose macronutrient fertilization, especially nitrogen, may influence the antioxidant enzyme system and the rate of lipid peroxidation. Depending on the degree of nitrogen fertilization, the rate of lipid peroxidation varies, thereby sharpening the transition at the end of the growing season and influencing senescence [17].

According to the study of Liu et al. [18], excessive nitrogen fertilization increased the rate of lipid peroxidation. Improper, low, or high levels of nitrogen fertilization may interfere with the antioxidant enzyme system's functioning and thereby increase malondialdehyde (MDA) levels.

Azooz et al. [19] found significant differences in maize hybrids' enzymatic responses to abiotic or biotic stress and the rate of lipid peroxidation, and abiotic stress-tolerant maize lines had lower levels of MDA under stress than conventional maize hybrids. Consequently, it is crucial to be aware of the nutrient- and intensity-dependent enzymatic responses of modern hybrids.

On the one hand, the yield increase of modern maize hybrids depends on the individual yield potential of the plant, which shows a continuously improving trend. On the other hand, as a result of the increasing homogeneity of the plant stock, the uniform height of individual plants also contributes to yield increase [20].

Analyzing SPAD values obtained in field conditions provides a reliable result on the degree of nitrogen supply. Plants can be measured nondestructively in different phases of the growing season. Several studies have examined the SPAD values of maize, in which the same results were found, i.e., SPAD readings are strongly related to nitrogen supply and, in particular, SPAD values show great differences between maize hybrids [21, 22]. Nitrogen fertilizer can increase the SPAD value, thereby increasing the relative chlorophyll content of plants.

Rapid, nondestructive content analysis of the crop is essential as different nitrogen treatments affect the protein content of the grain yield of maize hybrids. As the nitrogen supply increases, the grain yield's protein content also increases [23]. Oil content usually decreases with increasing nitrogen supply. However, different findings were obtained in this respect. According to Duarte et al. [24], the oil content of maize varies depending on the place of production in the same growing year, and the effect of nitrogen treatment on the decrease in oil yield cannot be demonstrated. According to the studies of Siam et al. [25], during the cultivation of maize with different nitrogen fertilizer active substances, the starch, oil, and protein content of the grain yield increased due to all applied forms of nitrogen (ammonium sulphate, ammonium gas, urea). Nitrogen as a nutrient is the second most crucial limiting factor after drought stress that determines plant biomass production and yield [26].

The present investigationt was aimed to determine the genetic yield potential of three examined maize genotypes within maximum input investment, medium fertilizer intensity, and without fertilizers and other yield-increasing substances as control.

Consequently, based on the information about the adaptability of the given hybrids and depending on their production intensity, it is possible to choose the best hybrid according to the prevailing agrotechnical standards and the farming inputs for the purpose of profitable, sustainable farming.

\section{Materials and Methods}

The experimental plants were three maize (Zea mays L.) hybrids with different FAO group of maturity: Hybrid 1FAO 400, Hybrid 2-FAO 490, and Hybrid 3-FAO 380. The study included three different $\mathrm{N}$ treatments $(0-\mathrm{NO}$ control treatment, $120-\mathrm{N} 1$ treatment, and $350 \mathrm{~kg} \cdot \mathrm{N} \cdot \mathrm{ha}^{-1}(\mathrm{~N} 2-$ treatment)) applied preplant and during the growing season. At the highest N2 dose, the applied amount of fertilizer was divided to $30 \mathrm{~kg} \cdot \mathrm{N}$ and $78 \mathrm{~kg} \mathrm{P}_{2} \mathrm{O}_{5}$ in the autumn; $135 \mathrm{~kg} \cdot \mathrm{N}+35 \mathrm{~kg} \mathrm{CaO}+25 \mathrm{~kg} \mathrm{MgO}$ in the spring during row cultivation; $\mathrm{N}+35 \mathrm{~kg} \mathrm{CaO}+25 \mathrm{~kg} \mathrm{MgO}$ in the period following the growing season (May-September). Macro- and microelements were released by means of drip irrigation. At the $\mathrm{N} 1$ nutrient level, $\mathrm{P}+\mathrm{K}$ application took place in the autumn, while nitrogen was applied before sowing in all cases. At the N0 nutrient level, no nutrient replenishment has taken place in any form since 1986, either in inorganic or inorganic form.

This examination focused on the level of agrotechnical support; in addition to the application of the N2 nutrient dose, $81 \mathrm{~nm}^{-1}$ drip irrigation was applied at the minimum value of the groundwater capacity every second day during the growing season at the eight-leaf stage (14/06) and grain filling (15/08). Irrigation was not applied at nutrient levels N0 and N1.

The relative chlorophyll content (SPAD unit) was always measured on the third youngest leaf. To monitor plant health and the state of the antioxidant defense system, the activity of ascorbate peroxidase and the rate of lipid peroxidation were measured based on the amount of MDA formed. Regarding photometric parameters, the examined phonological phases were determined based on heat sum, and the plant height was examined. Sampling was performed five 
times during the growing season. The following results were obtained as a result of sampling times based on heat sums and phonological phases:1st sampling, four leaves (heat sum: 153); 2nd sampling, six leaves (heat sum: 221); 3rd sampling, eight leaves (heat sum: 341); 4th sampling, 14 leaves (heat sum: 630), 5th sampling, silking (heat sum: 779).

After field sampling, samples were placed in liquid nitrogen and stored in an ultrafreezer at $-70^{\circ} \mathrm{C}$ until the determination of the measured parameters. In addition to yield measurement, starch, oil, protein, moisture content, and mass per volume were determined using a FOSS Infratech content tester. Near-infrared (NIR) spectroscopy offers a nondestructive method for the determination of starch, oil, protein, moisture content, and mass per volume [27].

Samples were taken from the $4^{\text {th }}$ (fully developed) leaf during the first three samplings, from the $10^{\text {th }}$ (fully developed) leaf at the $4^{\text {th }}$ sampling, and the leaf opposite to the ear at the last sampling. Samples were transported in liquid nitrogen and stored in a $-80^{\circ} \mathrm{C}$ deep freezer until processing.

The lipid peroxidation value was calculated from the amount of MDA with an extinction coefficient of $155 \mathrm{mM}^{-1} \cdot \mathrm{cm}^{-1}$, determined in the fresh weight of MDA $\mu \mathrm{mol}^{*} \mathrm{~g}^{-1} \mathrm{FW}$, based on the description of [28].

Calculation formula: Concentration of MDA $(\mathrm{mM})=($ ABS $532-$ ABS 600)/155.

The experiment is a two-factor, small-plot long-term field experiment with a strip-plot design and four replications, allowing for appropriate statistical evaluation. Four replications were applied during sampling, and the fifth replication was randomly selected from the first four ones.

The activity of ascorbate peroxidase was measured with a decrease in absorbance at $290 \mathrm{~nm}$ in 1 minute with a spectrophotometer based on the method of [29], with modifications by Janda et al. [30]. During sample processing, $0.5 \mathrm{~g}$ of the plant sample was crushed with isolation buffer, then centrifuged at $2^{\circ} \mathrm{C}$ for 20 minutes and stored on ice until measurement. $2 \mathrm{ml}$ of Tris- $\mathrm{HCl}$ solution and $100 \mu \mathrm{l}$ of ascorbate solution were added to $50 \mu$ l of plant sample during measurement. The decrease in 1 minute was determined, and $100 \mu \mathrm{l}$ of $\mathrm{H}_{2} \mathrm{O}_{2}$ was added to the same mixture. The difference between the two values was calculated from the $290 \mathrm{~nm}$ absorbance peroxide content.

Calculation form of APX: Enzyme activity (Units/ $\mathrm{L})=(\Delta \mathrm{ABS} \times$ Total assay volume $) /(\Delta t \times \varepsilon \times 1 \times$ Enzyme sample volume).

Extinction coefficient $=\varepsilon$ of substrates in units of $\mathrm{M}^{-1} \mathrm{~cm}^{-1}$, and $l$ is the cuvette diameter $(1 \mathrm{~cm})$. Enzyme activity (Unit) was defined as the amount of enzyme that oxidized $1 \mu \mathrm{mol}$ of substrate/min.

Analysis of variance is one of the most influential and widely used statistical techniques in economic, social, educational sciences, psychology, management, and even agriculture and biology. In cluster analysis, with $n$ individuals and measuring the variable $p$ in each individual, individuals grouped to be more similar in the same group [31]. Regression analysis studies the dependence of a variable (dependent variable) on another variable or several other variables (explanatory variable) by estimating or predicting the mean values of the first type variable if the importance of the second type variable is known (in sampling duplicate). The correlation coefficient ranges between one and minus one. A correlation coefficient between zero and one means a positive correlation, and the closer this coefficient is to one, the stronger the correlation is. The bi plot is a convenient tool for summarizing data and estimating response patterns that exist in the original data [32]. The biplot was performed with Genstat; variance analysis, correlation analysis, and cluster analysis were performed with SPSS during the statistical analysis.

\section{Results}

3.1. Variance Analysis. The effect of hybrids and treatments on yield, protein, oil, starch content, and APX was significant (Table 1).

The effect of sampling and treatment was significant in relation to APX and LP. Interaction treatments in sampling effect and interaction hybrids in sampling in treatments effect was significant on LP and APX. LP was significant on interaction hybrids in sampling (Table 1).

3.2. Regression Analysis. The regression analysis result showed significant V8 (8 fully developed leaves) APX and V6 (6 fully developed leaves) APX in yield, V14 LP and R1 (silking) APX in the oil content, V8 APX in the protein content, and V8 APX and V14 LP in the starch content in the first fertilizer treatment. V14 APX and R1 APX were significant in yield, SPAD (relative chlorophyll) in the oil content, V14 APX in the protein content, and V6 LP in the starch content in the first fertilizer treatments. Also, R1 LP and average LP were significant in yield, V6 LP and V8 LP in the oil content, V14 LP and V6 APX in the protein content, and V6 LP and moisture in the starch content in the third fertilizer treatment. Significant means that these parameters had a maximum effect on yield, protein, oil, and starch content (Table 2).

3.3. Cluster Analysis. The first fertilizer treatment (N0) showed that the first cluster included yield with plant height, relative chlorophyll content (SPAD value), V8 APX, V8 LP, and V4 LP. The second cluster included starch with V4 leaf APX. The third cluster included oil with V14 leaf APX, V14 leaf LP, R1, and average APX. Also, the fourth cluster included protein with mass per volume, V6 leaf APX, R1 LP, V6 LP, moisture, and average LP. The first cluster included protein content with plant height, mass per volume, V14 leaf APX, moisture, V4 leaf LP, and V6 LP, the second cluster included oil content with silking APX, and the third cluster included yield with chlorophyll content, V4 leaf APX, V14 leaf LP, starch, and R1LP in the second fertilizer treatment (N1). The first cluster included starch grouped with plant height, V6 leaf LP, R1 APX, average APX, V4 leaf APX, V6 leaf APX, and R1LP, the second cluster included protein with chlorophyll, mass per volume, and V14 leaf APX, and the third cluster included yield with V8 leaf APX, moisture, V6 leaf LP and Oilin the third fertilizer treatment (N2) (Figure 1.). 


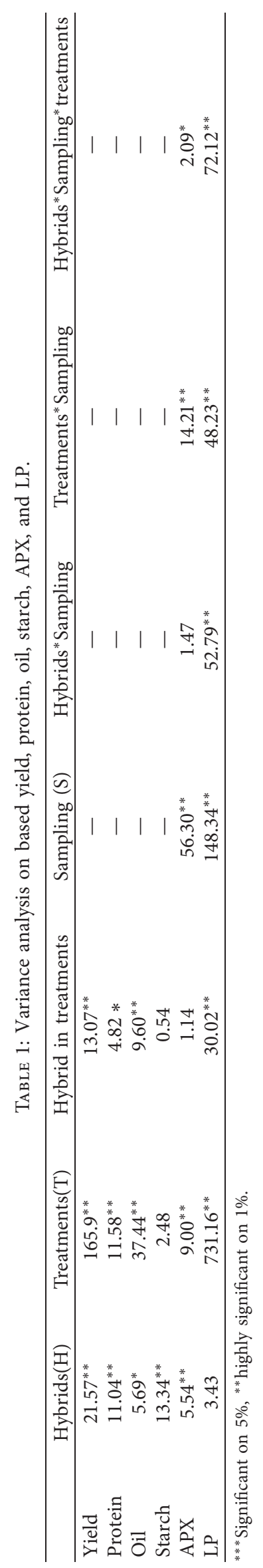


TABLE 2: Regression analysis of the treatments on maize hybrids.

\begin{tabular}{|c|c|c|c|}
\hline Treatment & Variable & Equation & Parameter \\
\hline No & $\begin{array}{l}\text { Yield } \\
\text { Oil } \\
\text { Protein } \\
\text { Starch }\end{array}$ & $\begin{array}{c}Y=-9.80+1.46 X 1+1.15 X 2 \\
Y=-4.605+0.14 X 1+0.01 X 2 \\
Y=10.24-0.45 X 1 \\
Y=-101.5-2.703 X 1+6.447 X 2\end{array}$ & $\begin{array}{c}X 1: \text { 8leafAPX, } X 2: \text { 6leafAPX } \\
X 1: \text { 14leafLP, } X 2 \text { : Silking APX } \\
X 1: \text { 8leafAPX } \\
X 1: 8 \text { leaf APX, } X 2: 14 \text { leaf LP }\end{array}$ \\
\hline N1 & $\begin{array}{l}\text { Yield } \\
\text { Oil } \\
\text { Protein } \\
\text { Starch }\end{array}$ & $\begin{array}{c}Y=8.88-1.39 X 1+0.44 X 2 \\
Y=5.80-0.03 \\
Y=7.30+0.18 X 1 \\
Y=90.71-4.17 X 1\end{array}$ & $\begin{array}{c}\text { X1: 14leaf APX, X2: Silking APX } \\
X 1: \text { SPAD } \\
X 1: 14 \text { leafAPX } \\
X 1: 6 \text { leaf LP }\end{array}$ \\
\hline $\mathrm{N} 2$ & $\begin{array}{l}\text { Yield } \\
\text { Oil } \\
\text { Protein } \\
\text { Starch }\end{array}$ & $\begin{array}{c}Y=2.60-3.72 X 1+4.39 X 2 \\
Y=4.92+0.57 X 1-0.71 X 2 \\
Y=2.56-0.43 X 1+0.13 X 2 \\
Y=80.51-10.52 X 1+2.39 X 2\end{array}$ & $\begin{array}{c}X 1: \text { silking LP, } X 2: \text { Average LP } \\
X 1: 6 \text { leaf LP, } X 2: 8 \text { leaf LP } \\
X 1: \text { 14leafLP, } X 2: \text { 6leafAPX } \\
X 1: 6 \text { leaf LP, } X 2: \text { moisture }\end{array}$ \\
\hline
\end{tabular}

N0

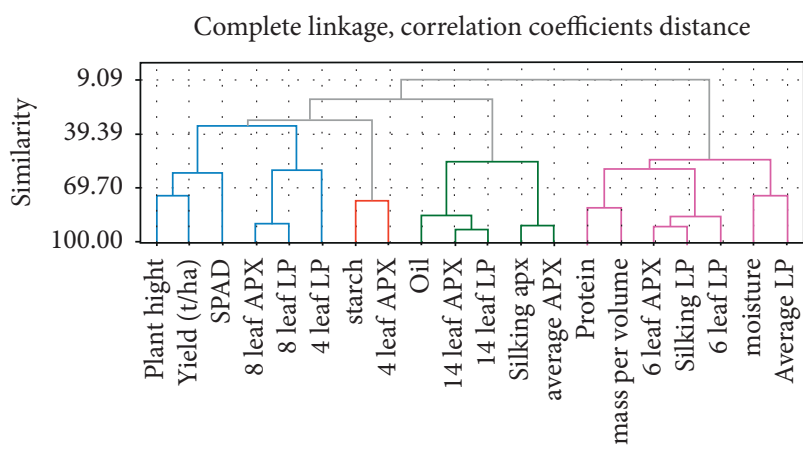

Variables

(a)
$\mathrm{N} 1$

Dendrogram

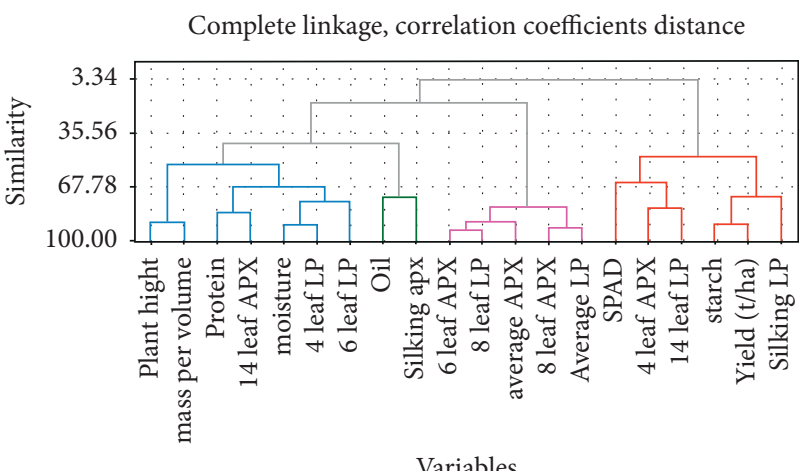

(b)

$\mathrm{N} 2$

Dendrogram

Complete linkage, correlation coefficients distance

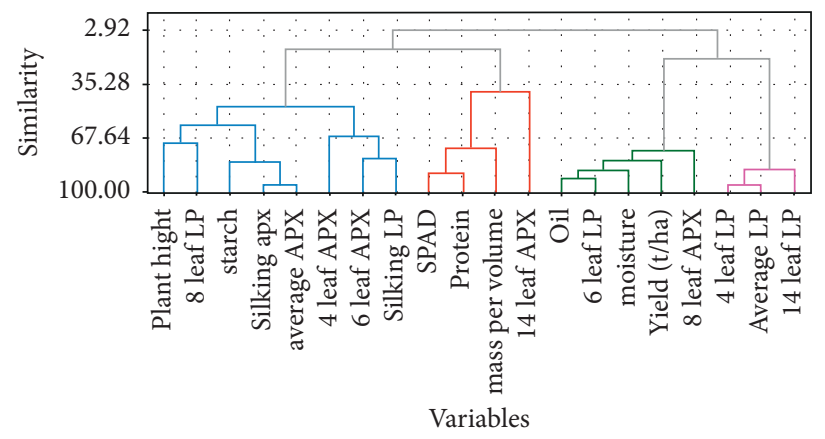

(c)

Figure 1: Cluster analysis traits on treatment.

3.4. Correlation Analysis. Oil had a positive correlation with $14^{\text {th }}$ leaf APX, average APX, $14^{\text {th }}$ leaf LP, average LP, and negative correlation with $6^{\text {th }}$ leaf LP. Protein had a positive correlation with moisture, mass per volume, $6^{\text {th }}$ leaf APX, and negative correlation with yield and 8th leaf APX. Moisture had a positive correlation with yield, $8^{\text {th }}$ leaf APX, and $8^{\text {th }}$ leaf LP and a negative correlation with silking LP and protein. Mass per volume had a positive correlation with $6^{\text {th }}$ leaf APX, silking LP, and negative correlation with $8^{\text {th }}$ leaf APX and $8^{\text {th }}$ leaf LP. The yield had a positive correlation with $8^{\text {th }}$ leaf APX and a negative correlation with protein and moisture in the first fertilizer treatment. Oil had a negative correlation with SPAD values and protein had a positive correlation with $14^{\text {th }}$ leaf APX and $6^{\text {th }}$ leaf LP and negative correlation with yield, silking LP and SPAD values. Starch had a positive correlation with yield, $14^{\text {th }}$ leaf LP and negative correlation with protein, moisture, $14^{\text {th }}$ leaf APX, and $6^{\text {th }}$ leaf LP. Moisture had a positive correlation with $4^{\text {th }}$ leaf LP and $6^{\text {th }}$ leaf LP, and a negative correlation with yield, $4^{\text {th }}$ leaf APX, $14^{\text {th }}$ leaf LP, 
average LP, and starch. Mass per volume had a positive correlation with plant height; the yield had a positive correlation with silking LP and starch and a negative correlation with $14^{\text {th }}$ leaf APX and protein and moisture in the second fertilizer treatment.

Oil had a positive correlation with moisture, mass per volume, yield, $8^{\text {th }}$ leaf APX, $6^{\text {th }}$ leaf LP, and negative correlation with $8^{\text {th }}$ leaf LP, silking LP, average LP, starch. Starch had a positive correlation with silking APX, average APX, $8^{\text {th }}$ leaf LP, silking LP, and a negative correlation with oil, mass per volume, $8^{\text {th }}$ leaf APX, and $6^{\text {th }}$ leaf LP. Protein had a positive correlation with mass per volume, $6^{\text {th }}$ leaf APX, SPAD value, and negative correlation with $14^{\text {th }}$ leaf LP, average LP. Moisture had a positive correlation with yield, $8^{\text {th }}$ leaf APX, $6^{\text {th }}$ leaf LP, oil, and negative correlation with $8^{\text {th }}$ leaf LP and silking LP. Mass per volume had a positive correlation with $6^{\text {th }}$ leaf LP, oil, protein, and a negative correlation with $4^{\text {th }}$ leaf LP, $8^{\text {th }}$ leaf LP, $14^{\text {th }}$ leaf LP, average LP, and starch. The yield had a positive correlation with silking LP, oil, moisture, and a negative correlation with SPAD value in the (N2) fertilizer treatment (Table 3).

3.5. Bi Plot Analysis. The DKC 1 hybrid had the maximum yield in this study. Also, silking LP and V4 LP had a full effect on yield. V8 leaf APX had the maximum impact on SY Premeo hybrid based on their yield. V6 leaf LP, V4 leaf LP, average LP, V14 leaf LP, V8 leaf LP, and V6 leaf APX had the maximum effect on oil percentage, and R1 LP, V4 leaf APX. Silking leaf APX had maximum impact on starch. V6 leaf APX, V6 leaf LP, V4 leaf LP, average leaf LP, and V14 leaf LP had maximum effect on the protein (Figure 2).

This research indicated that LP, APX had various treatments sampling, interaction treatments in sampling, and hybrids in sampling in treatments. The leaf stage of LP had the maximum effect on yield, and V6 leaf APX had its maximum effect on oil content. Nitrogen fertilizer may affect the LP and APX index. Decreasing the amount of APX in V14 leaf is needed to achieve increasing yield. In contrary, higher level APX in V14 and V6 is needed for increasing protein content, and raising APX in V14 and V8 leaf to achieve higher oil content.

\section{Discussion}

The activation of lipid peroxidation and the activity of APX under nitrogen fertilizer conditions may affect the plant's physiology parameters. In this study, correlation and biplot analysis show that increases in the plant's LP level cause a decrease in the plant's oil performance. The amount of APX and LP at the 6-leaf-level directly affects protein content. The amount of APX at the silking stage has a direct and significant effect on starch. This study showed that the amount of APX during silking has the highest value in all hybrids in the performed treatments. Increasing fertilizer treatment had a significant effect on APX at all measurement stages. Increasing the fertilizer treatment slightly increases the concentration of LP in the plant. The SY Premeo hybrid had the highest yield based on GGE analysis and the highest concentrations of APX and LP at different fertilizer levels. Maize is one of the plants with the highest sensitivity to elemental zinc deficiency due to its biochemical needs (Marschner, 1995) [33]. Drought stress, similarly to other environmental stresses, causes oxidative damage. Oxidative damage caused by oxygen radicals includes oxidative damage to lipids, proteins, and DNA. In this regard, the production of active oxygen species leads to peroxidation. Plants for protection against reactive oxygen species used (ROS for excretion of antioxidants such as superoxide dismutase compounds) (SOD and catalase) (COD and catalase). Plants begin enzymatic (SOD, APX) and nonenzymatic (ascorbate, carotenoids, tocopherols, glutathione) defense devices to get oxidative homeostasis [34]. Researchers reported developed APX actions in the case of drought-tolerant maize varieties, while sensitive types showed decreased APX. These results suggested that increased APX activity might be an adaptive response to drought [35]. Zhang and Kirkham [36] used drought stress on sunflower and sorghum grains in pot experiments by constant watering. They reported that the sunflower APX enzyme activity was not influenced by applied drought stress, while sorghum plants decreased their APX activity significantly. In addition, the researchers suggested that this finding might indicate a more significant accumulation of $\mathrm{H}_{2} \mathrm{O}_{2}$ in cells that can result in decreased synthesis of APX and extended degradation of enzymes.

Consequently, nitrogen increase could alleviate lipid peroxidation by expanding antioxidant enzymes' activities and decreasing malondialdehyde (MDA) content to sustain the leaves' photosynthetic function under water stress [37]. Similar results were observed in wheat [38] and tobacco leaf tissue [39]. Saneoka et al. [40] stated that MDA concentration decreased with increased $\mathrm{N}$ application in waterstressed plants. Such reduction in malondialdehyde (MDA) content accumulation at higher $\mathrm{N}$ levels showed an adequate supply of nitrogen could alleviate water stress effects by decreasing lipid peroxidation. The obtained results suggest that the increase of nitrogen expands production and drought tolerance in crops by improving antioxidant enzyme activities and decreasing lipid peroxidation. In addition, better effectiveness of nitrogen is shown in a watersensitive variety compared to a drought-tolerant one. The extended magnitude is higher under water stress than under adequate water supply [41]. The interaction between ozone and nitrogen fertilizer modifies the $\mathrm{Chl}$ parameters, raises lipid peroxidation, and reduces watermelon yields [42]. This study showed that the increased rate of LP caused a decrease in grain yield, oil content, protein, and starch in maize. Increasing the activity of APX also reduces yield. Increasing the APX level is directly correlated with the oil percentage. Nitrogen fertilization controls APX and LP under environmental and biological stresses. Mao et al. [43] recommend that fertilizer application is directly associated with physiological reactions in the maize plant. It shows the output of oxygen radicals as the plants revealed a significant gain in SOD, CAT, POD, APX, and GR activity in the leaves, which resulted in raising lipid peroxidation and oxidation in the plant. In summary, the level of agrotechnical support can cause a different effect on the physiological parameters of 


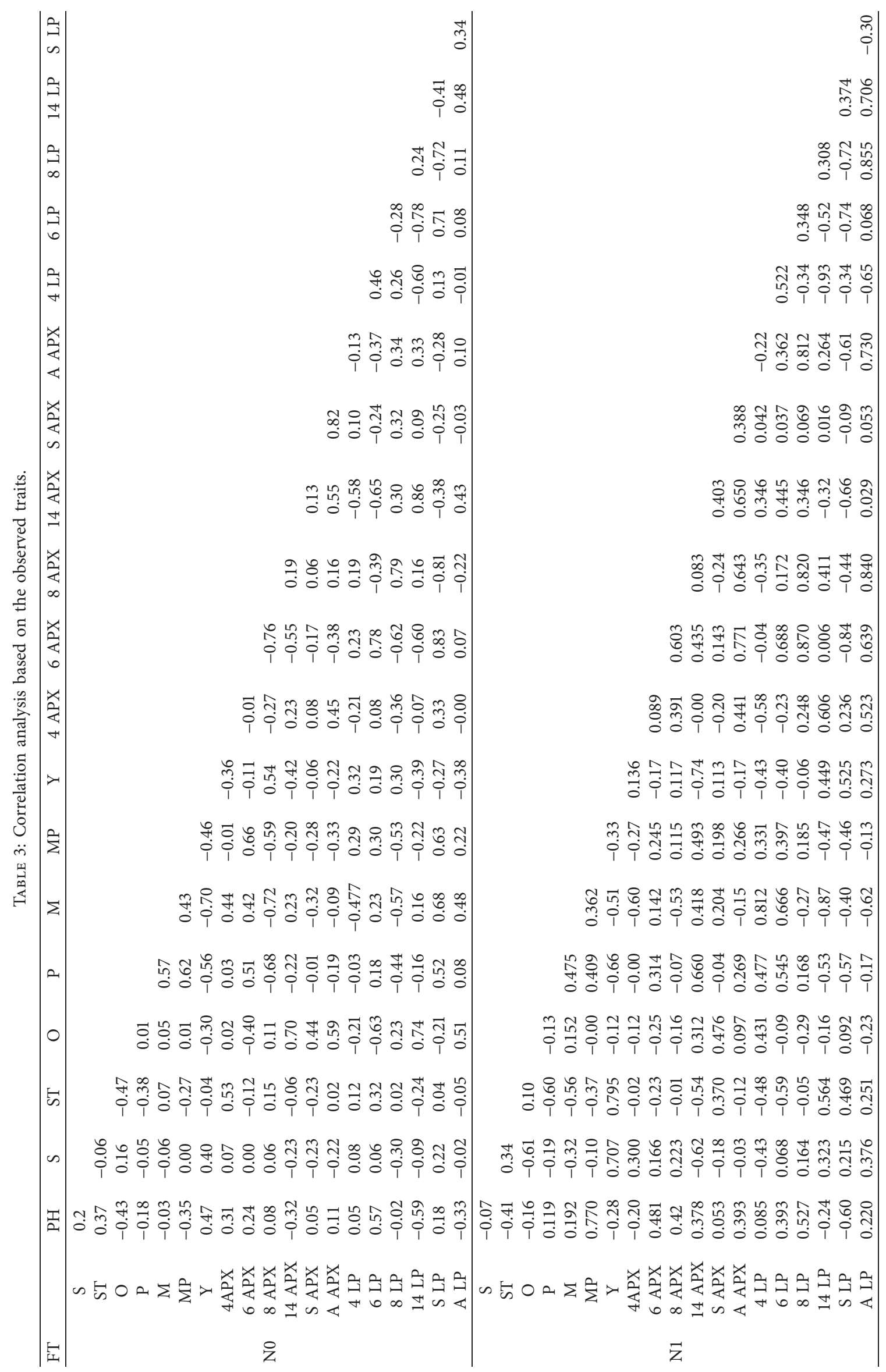




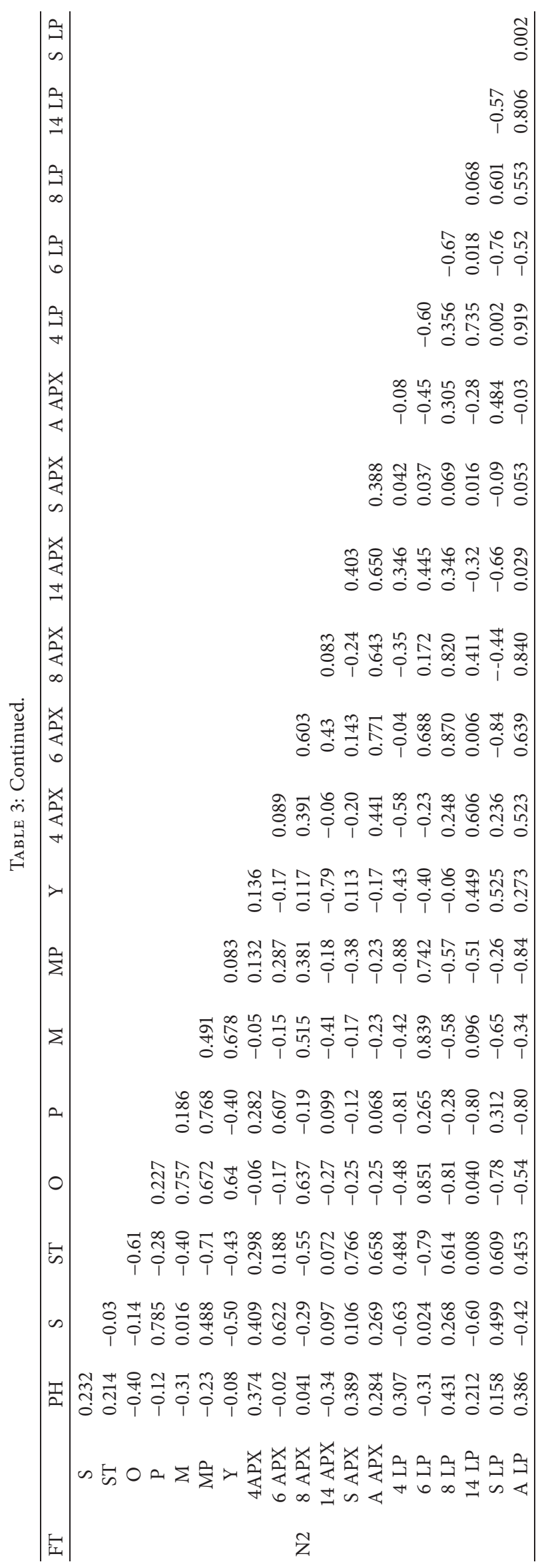




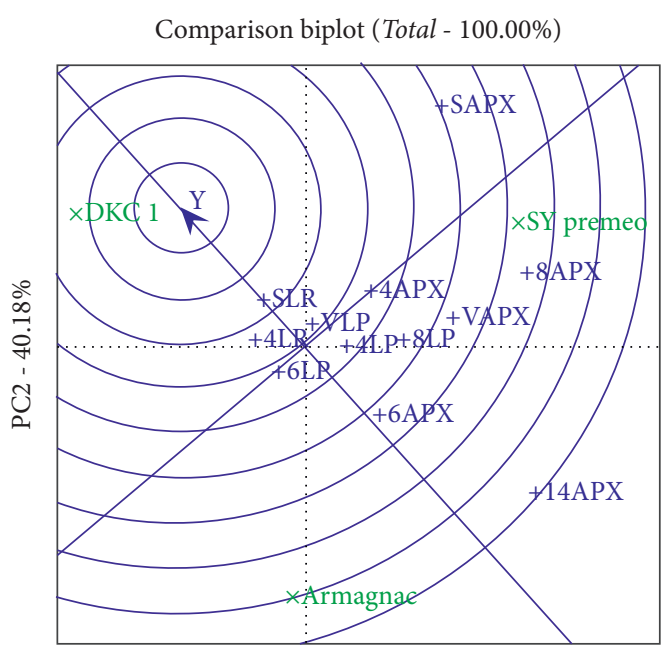

PC1 - 59.82\%

$\times$ Genotype scores

+ Environment scores

O AEC

(a)

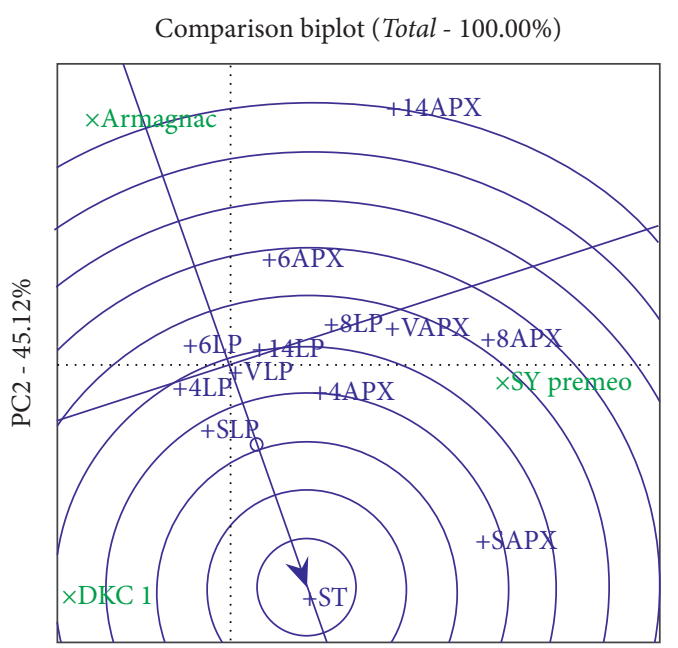

PC1 - 54.88\%

$\times$ Genotype scores

+ Environment scores

O AEC

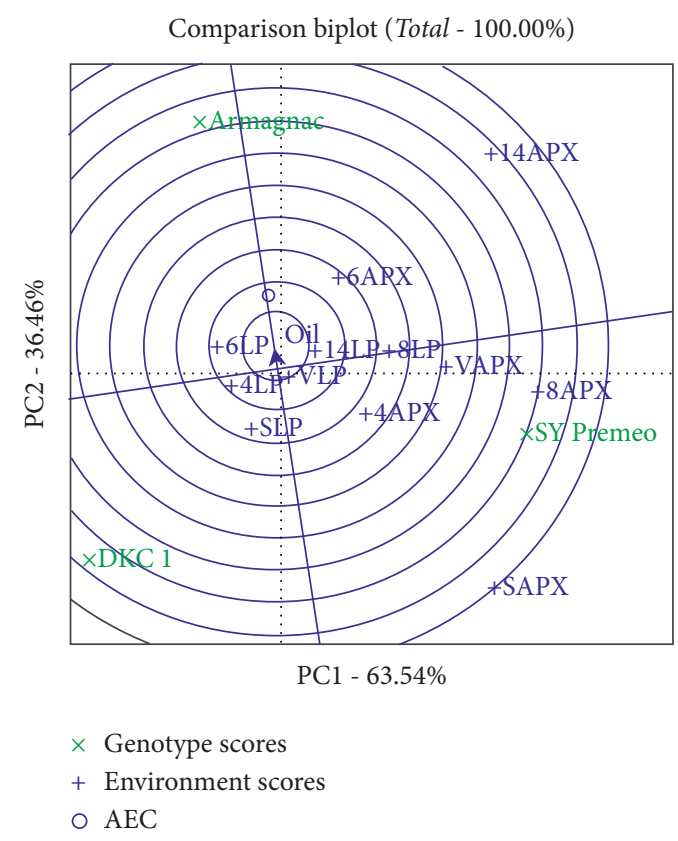

(b)

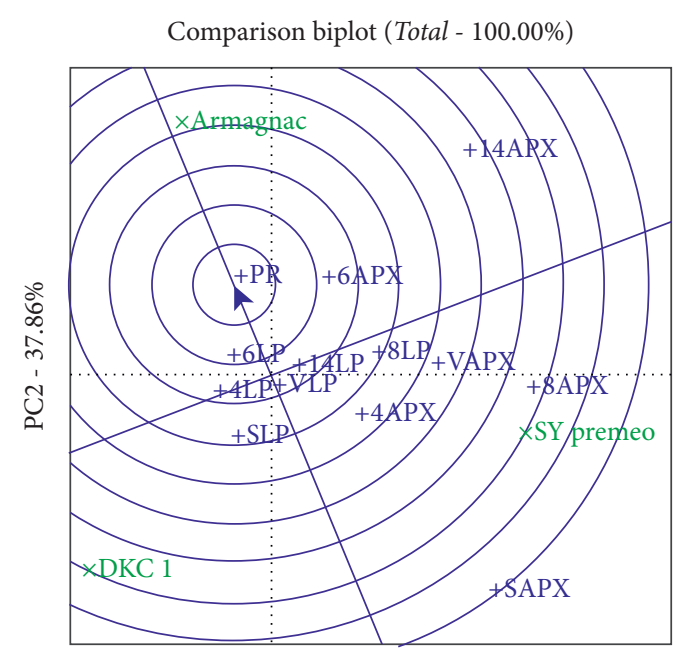

PC1 - 62.14\%

$\times$ Genotype scores
+ Environment scores
○ AEC

(d)

(c)

Figure 2: Bi plot average traits on based yield, oil, starch, and protein.

maize during the growing season. Therefore, we need to take it into account when designing technology.

\section{Conclusion}

This study showed that the increased LP amount causes a decrease in grain yield, oil content, protein, and starch in the plant. Increasing the APX level also reduces yield. Increasing the APX level is directly correlated with the oil percentage. Nitrogen fertilizer controls and uniform APX and LP under environmental and biological stresses.

\section{Data Availability}

The data used to support the findings of this study are available from the corresponding author upon request.

\section{Consent}

Consent by the authors (Árpád Illés, Csaba Bojtor, Adrienn Széles, Seyed Mohammad Nasir Mousavi, Brigitta Tóth, and János Nagy) was given to publish their results. 


\section{Conflicts of Interest}

The authors declare that they have no conflicts of interest.

\section{Authors' Contributions}

Árpád Illés and János Nagy supervised the experiment and wrote the manuscript. Csaba Bojtor and Adrienn Széles performed the experiments and collected samples in the field. Seyed Mohammad Nasir Mousavi made a statistical analysis and reviewed the manuscript to submit. Brigitta Tóth made the figures and reviewed the manuscript.

\section{Acknowledgments}

The research was financed by the UNKP-20-3 New National Excellence Program of the Ministry for Innovation and Technology and Project no. TKP2020-IKA-04 has been implemented with the support provided by the National Research, Development and Innovation Fund of Hungary, financed under the 2020-4.1.1-TKP2020 funding scheme.

\section{References}

[1] O. Blokhina, E. Virolainen, and V. Kurt, "Antioxidants, oxidative damage and oxygen deprivation stress: a review," Annals of Botany, vol. 91, no. 2, pp. 179-194, 2003.

[2] A. Caverzan, G. Passaia, S. B. Rosa, C. W. Ribeiro, F. Lazzarotto, and M. Margis-Pinheiro, "Plant responses to stresses: role of ascorbate peroxidase in the antioxidant protection," Genetics and Molecular Biology, vol. 35, no. 4, pp. 1011-1019, 2012.

[3] W. M. Kaiser, "Reversible inhibition of the Calvin cycle and activation of oxidative pentose phosphate cycle in isolated intact chloroplasts by hydrogen peroxide," Planta, vol. 145, no. 4, pp. 377-382, 1979.

[4] J. M. Robinson, M. G. Smith, and M. Gibbs, "Influence of hydrogen peroxide upon carbon dioxide photoassimilation in the spinach chloroplast," Plant Physiology, vol. 65, no. 4, pp. 755-759, 1980.

[5] S. Elavarthi and B. Martin, "Spectrophotometric assays for antioxidant enzymes in plants," in Plant Stress Tolerance, pp. 273-280, Humana Press, Totowa, NJ, USA, 2010.

[6] S. Kawakami, Y. Matsumoto, A. Matsunaga, S. Mayama, and M. Mizuno, "Molecular cloning of ascorbate peroxidase in potato tubers and its response during storage at low temperature," Plant Science, vol. 163, no. 4, pp. 829-836, 2002.

[7] K. Smeets, J. Ruytinx, B. Semane et al., "Cadmium-induced transcriptional and enzymatic alterations related to oxidative stress," Environmental and Experimental Botany, vol. 63, no. 1-3, pp. 1-8, 2008.

[8] I. Khan, A. Ahmad, and M. Iqbal, "Modulation of antioxidant defence system for arsenic detoxification in Indian mustard," Ecotoxicology and Environmental Safety, vol. 72, no. 2, pp. 626-634, 2009.

[9] Y. K. Markovska, N. I. Gorinova, M. P. Nedkovska, and K. M. Miteva, "Cadmium-induced oxidative damage and antioxidant responses in Brassica juncea plants," Biologia Plantarum, vol. 53, no. 1, pp. 151-154, 2009.

[10] I. Nouairi, W. Ben Ammar, N. Ben Youssef, D. D. Ben Miled, M. H. Ghorbal, and M. Zarrouk, "Antioxidant defense system in leaves of Indian mustard (Brassica juncea) and rape
(Brassica napus) under cadmium stress," Acta Physiologiae Plantarum, vol. 31, no. 2, pp. 237-247, 2009.

[11] A. P. Pinto, A. S. Alves, A. J. Candeias et al., "Cadmium accumulation and antioxidative defences in Brassica juncea L. Czern, Nicotiana tabacum L. and Solanum nigrum L.," International Journal of Environmental and Analytical Chemistry, vol. 89, no. 8-12, pp. 661-676, 2009.

[12] S. Karpinski, H. Reynolds, B. Karpinska, G. Wingsle, C. Gary, and P. Mullineaux, "Systemic signaling and acclimation in response to excess excitation energy in Arabidopsis," Science, vol. 284, no. 5414, pp. 654-657, 1999.

[13] I. Yordanov, V. Velikova, and T. Tsonev, "Plant responses to drought, acclimation, and stress tolerance," Photosynthetica, vol. 38, no. 2, pp. 171-186, 2000.

[14] S. Bhattacharjee, "Membrane lipid peroxidation and its conflict of interest: the two faces of oxidative stress," Current Science, vol. 107, no. 11, pp. 1811-1823, 2014.

[15] D. Prochazkova, R. K. Sairam, G. C. Srivastava, and D. V. Singh, "Oxidative stress and antioxidant activity as the basis of senescence in maize leaves," Plant Science, vol. 161, no. 4, pp. 765-771, 2001.

[16] X.-m. Zhan, X.-r. Han, J.-f. Yang, S. Wang, M. Gao, and L.-y. Zhao, "Effect of different fertilizer supply of maize on protective enzyme activities and lipid peroxidation of leaves in latter stage," Journal of Maize Sciences, vol. 1, 2007.

[17] Á. Illés, C. Bojtor, S. M. Nasir Mousavi, L. Csaba Marton, P. . Ragán, and J. . Nagy, "Maize hybrid and nutrient specific evaluation of the population dynamics and damage of the western corn rootworm (Diabrotica Virgifera Virgifera LeConte) in a long-term field experiment," Progress in Agricultural Engineering Sciences, vol. 16, no. 1, 2020.

[18] L. Yan, R. Wang, L. Hua, and Z.J. Xie, "Effects of N applied rate on leaf senescence and protective enzyme system at later growth stage of maize," Journal of Maize Sciences, vol. 20, no. 2, pp. 124-127, 2012.

[19] M. M. Azooz, A. M. Ismail, and M. F. A. Elhamd, "Growth, lipid peroxidation and antioxidant enzyme activities as a selection criterion for the salt tolerance of maize cultivars grown under salinity stress," International Journal of Agriculture and Biology, vol. 11, no. 1, pp. 21-26, 2009.

[20] I. S. Tokatlidis and S. D. Koutroubas, "A review of maize hybrids' dependence on high plant populations and its implications for crop yield stability," Field Crops Research, vol. 88, no. 2-3, pp. 103-114, 2004.

[21] C. Costa, L. M. Dwyer, P. Dutilleul et al., "Inter-relationships of applied nitrogen, SPAD, and yield of leafy and non-leafy maize genotypes," Journal of Plant Nutrition, vol. 24, no. 8, pp. 1173-1194, 2001.

[22] G. Argenta, P. R. F. d. Silva, and L. Sangoi, "Leaf relative chlorophyll content as an indicator parameter to predict nitrogen fertilization in maize," Ciência Rural, vol. 34, no. 5, pp. 1379-1387, 2004.

[23] A. C. Ulger, H. Ibrikci, B. Cakir, and N. Guzel, "Influence of nitrogen rates and row spacing on corn yield, protein content, and other plant parameters," Journal of Plant Nutrition, vol. 20, no. 12, pp. 1697-1709, 1997.

[24] A. P. Duarte, S. C. Mason, D. S. Jackson, and J. d. C. Kiehl, "Grain quality of Brazilian maize genotypes as influenced by nitrogen level," Crop Science, vol. 45, no. 5, pp. 1958-1964, 2005.

[25] H. S. Siam, G. A. Mona, and H. I. El-Alia, "Yield and yield components of maize as affected by different sources and application rates of nitrogen fertilizer," Research Journal of 
Agriculture and Biological Sciences, vol. 4, no. 5, pp. 399-412, 2008.

[26] H. Yang, J. Yang, Y. Lv, and J. He, "SPAD values and nitrogen nutrition index for the evaluation of rice nitrogen status," Plant Production Science, vol. 17, no. 1, pp. 81-92, 2014.

[27] J. Janni, B. R. Weinstock, L. Hagen, and S. Wright, "Novel near-infrared sampling apparatus for single kernel analysis of oil content in maize," Applied Spectroscopy, vol. 62, no. 4, pp. 423-426, 2008.

[28] B. Ventura and R. Roberto, "Antioxidant metabolism of Panicum maximum and Stylosanthes capitata under climate change," 2019.

[29] Y. Nakano and K. Asada, "Hydrogen peroxide is scavenged by ascorbate-specific peroxidase in spinach chloroplasts," Plant and Cell Physiology, vol. 22, no. 5, pp. 867-880, 1981.

[30] T. Janda, G. Szalai, I. Tari, and E. Páldi, "Hydroponic treatment with salicylic acid decreases the effects of chilling injury in maize (Zea mays L.) plants," Planta, vol. 208, no. 2, pp. 175-180, 1999.

[31] S. Mousavi and J. Nagy, "Evaluation of plant characteristics related to grain yield of FAO410 and FAO340 hybrids using regression models," Cereal Research Communications, pp. 1-9, 2020.

[32] Á. Illés, S. M. N. Mousavi, C. Bojtor, and J. Nagy, “The plant nutrition impact on the quality and quantity parameters of maize hybrids grain yield based on different statistical methods," Cereal Research Communications, vol. 48, no. 4, pp. 565-573, 2020.

[33] H. Marschner, Mineral Nutrition of High Plant, pp. 330-355, Academic Press, Cambridge, MA, USA, 1995.

[34] C. de Carvalho and H. Maria, "Drought stress and reactive oxygen species: production, scavenging and signaling," Plant Signaling \& Behavior, vol. 3, no. 3, pp. 156-165, 2008.

[35] Ö. Çelik, A. Alp, and Ç. Atak, "Enzymatic and non-enzymatic comparison of two different industrial tomato (Solanum lycopersicum) varieties against drought stress," Botanical Studies, vol. 58, pp. 32-1, 2017.

[36] J. Zhang and M. B. Kirkham, "Antioxidant responses to drought in sunflower and sorghum seedlings," New Phytologist, vol. 132, no. 3, pp. 361-373, 1996.

[37] Z. W. Jiang, W. X. Lin, Y. Z. Li, C. Y. Zhuo, H. J. Yang, and H. A. Xie, "Effects of nitrogen fertilizer rates on some physiological characteristics of ratoon rice," Fujian Journal of Agricultural Sciences, vol. 20, pp. 168-171, 2005.

[38] G. S. Zhang and R. S. Zhang, "Effects of N and P on the activities of protective enzyme in wheat seedling under water deficit," Journal of Gansu Agricultural University, vol. 3, pp. 285-289, 2003.

[39] J. H. Zhou, Y. T. Wang, J. B. Yu, and D. Cheng, "Effect of nitrogen form on the activities of protective enzyme in tobacco leaves under drought condition," Journal of Chinese Tobacco Science, vol. 2, pp. 5-8, 2001.

[40] H. Saneoka, R. E. A. Moghaieb, G. S. Premachandra, and K. Fujita, "Nitrogen nutrition and water stress effects on cell membrane stability and leaf water relations in Agrostis palustris Huds," Environmental and Experimental Botany, vol. 52, no. 2, pp. 131-138, 2004.

[41] L.-X. Zhang, S.-X. Li, H. Zhang, and Z.-S. Liang, "Nitrogen rates and water stress effects on production, lipid peroxidation and antioxidative enzyme activities in two maize (Zea mays L.) genotypes," Journal of Agronomy and Crop Science, vol. 193, no. 6, pp. 387-397, 2007.

[42] A. Calatayud, F. Pomares, and E. Barreno, "Interactions between nitrogen fertilization and ozone in watermelon cultivar Reina de Corazones in open-top chambers. effects on chlorophyll a fluorescence, lipid peroxidation, and yield," Photosynthetica, vol. 44, no. 1, pp. 93-101, 2006.

[43] S. Mao, M. R. Islam, Y. Hu, X. Qian, F. Chen, and X. Xue, "Antioxidant enzyme activities and lipid peroxidation in corn (Zea mays L.) following soil application of superabsorbent polymer at different fertilizer regimes," African Journal of Biotechnology, vol. 10, no. 49, pp. 10000-10008, 2011. 